\title{
An Efficient Wind-Photovoltaic Hybrid Generation System Using Doubly Excited Permanent-Magnet Brushless Machine
}

\author{
Chunhua Liu, Member, IEEE, K. T. Chau, Senior Member, IEEE, and \\ Xiaodong Zhang, Student Member, IEEE
}

\begin{abstract}
With ever-increasing concerns on energy issues, the development of renewable energy sources is becoming more and more attractive. This paper first reviews both the wind power and photovoltaic (PV) power generation techniques and their maximum-power-point tracking (MPPT) methods. Then, a new stand-alone wind-PV hybrid generation system is proposed for application to remote and isolated areas. For the wind power generation branch, a new doubly excited permanent-magnet brushless machine is used to capture the maximum wind power by using online flux control. For the PV power generation branch, a single-ended primary inductance converter is adopted to harness the maximum solar power by tuning the duty cycle. The experimental results confirm that the proposed hybrid generation system can provide high efficiency with the use of MPPT.
\end{abstract}

Index Terms-Maximum-power-point tracking (MPPT), permanent-magnet (PM) brushless machine, photovoltaic (PV), wind power.

\section{INTRODUCTION}

W ITH their advantages of being abundant in nature and nearly nonpollutant, renewable energy sources have attracted wide attention. Wind power is one of the most promising clean energy sources since it can easily be captured by wind generators with high power capacity. Photovoltaic (PV) power is another promising clean energy source since it is global and can be harnessed without using rotational generators. In fact, wind power and PV power are complementary to some extent since strong winds are mostly to occur during the nighttime and cloudy days whereas sunny days are often calm with weak winds [1]. Hence, a wind-PV hybrid generation system can offer higher reliability to maintain continuous power output than any other individual power generation systems. In those remote or isolated areas, the stand-alone wind-PV hybrid generation system is particularly valuable and attractive.

The electric machine is the key for electromechanical energy conversion, which has widely been used for various applications such as wind power generation [2], [3] and electric vehicle propulsion [4]-[6]. Focusing on wind power generation, different kinds of electric machines have been developed as

Manuscript received November 28, 2008; revised May 1, 2009. First published May 15, 2009; current version published February 10, 2010. This work was supported by the Research Grants Council, Hong Kong Special Administrative Region, under Grant HKU 7105/07E.

The authors are with the Department of Electrical and Electronic Engineering, The University of Hong Kong, Pokfulam, Hong Kong (e-mail: chualiu@eee.hku.hk; ktchau@eee.hku.hk; xiaodong@eee.hku.hk).

Digital Object Identifier 10.1109/TIE.2009.2022511

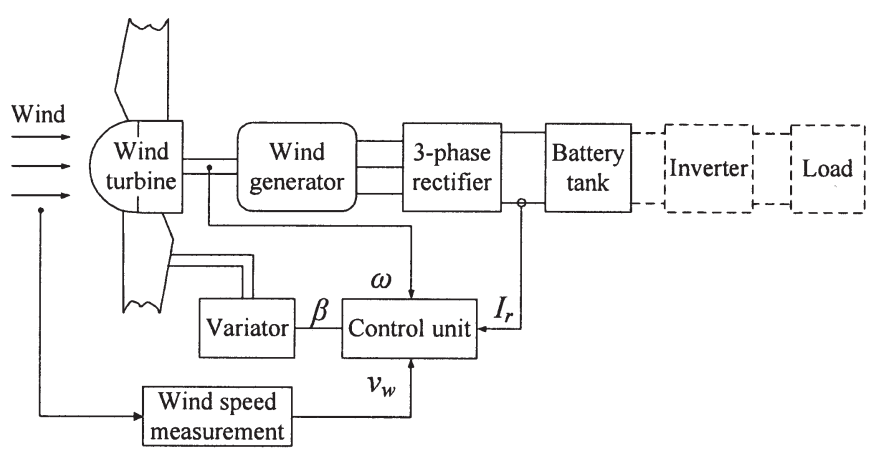

(a)

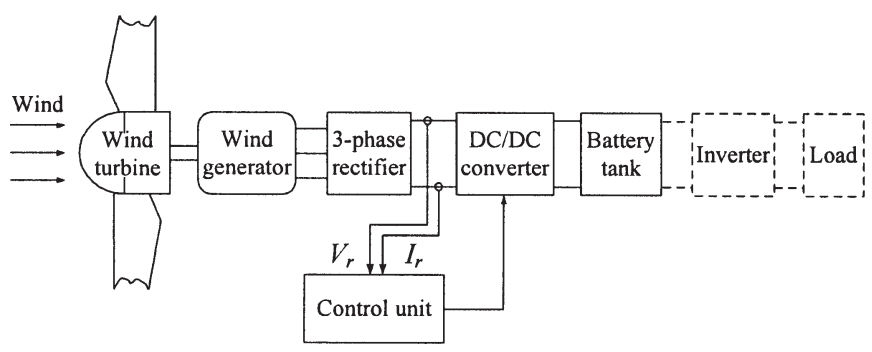

(b)

Fig. 1. Typical wind power generation systems. (a) TSR method. (b) PAO method.

wind generators, including induction machines [7], permanentmagnet (PM) brushless machines [8], [9], switched reluctance machines [10], and doubly salient PM machines [11]. However, most of these wind generators are designed to simply capture the wind power but do not intend to produce the maximum power. Recently, some methods have been proposed to realize the maximum wind power extraction. Generally, these methods can be classified into two main types. The first type is to obtain the maximum mechanical power (wind turbine output power) at a given wind speed by regulating the tip speed ratio (TSR) of the turbine [12]. As shown in Fig. 1(a), this method has to measure the wind speed and the turbine speed. Since the wind speed measurement is difficult and costly, the implementation of this method is quite limited. Also, the optimal value of TSR has to be revised when the generation system is altered. The second type is to produce the maximum electrical power (generator output power or converter output power) at a given wind speed by controlling the power converter with the use of the hillclimbing search or perturb-and-observe (PAO) method [13]. As shown in Fig. 1(b), it can eliminate the drawbacks of the aforementioned method because it does not need to measure the 
wind speed and is system independent. Although it has to spend additional cost and install an additional power converter to perform maximum-power-point tracking (MPPT), this method is widely accepted because of easy implementation [14].

For PV power generation, it usually consists of an array of PV panels and a power converter. By regulating the converter, the maximum power point of the PV panels can be tracked. Over the years, different MPPT techniques have been proposed for PV power generation [15]-[17]. These methods mainly include the PAO, the power matching, the incremental conductance, the fractional open-circuit voltage/short-circuit current, the power differential feedback control, the curve fitting, the dc-link capacitor droop control, the intelligent control, and some other special control methods [18]-[20]. Among them, the PAO method is adopted by most researchers because of its simplicity and system independence.

For wind-PV hybrid power generation, it has two branches-namely, the wind power generation and the PV power generation. Since the wind power and PV power can compensate each other to some extent during the day and night, the development of the wind-PV hybrid power generation is attractive. This kind of hybrid generation system can be divided into two main types - the stand-alone off-grid system [21], [22] and the grid-connected system [23]. For the grid-connected system, the interface between the hybrid generation system and the power grid has to be specially designed which involves costly hardware and complex control. For the stand-alone offgrid system, the hybrid generation system can easily be set up in remote and isolated areas where a connection to the utility network is either impossible or unduly expensive. Over the years, there have been only a few research works on the standalone wind-PV hybrid generation system [21], [22] in which the wind generators are focused on induction machines.

The purpose of this paper is to present a new stand-alone wind-PV hybrid generation system for remote or isolated areas. The keys are to perform flux control of the wind generator so as to extract the maximum power from the wind turbine and to perform duty cycle control of the single-ended primary inductance converter (SEPIC) so as to harness the maximum power from the PV panels. Hence, this hybrid generation system forms a highly independent generation system from day to night.

\section{SYSTEM CONFIGURATION}

Fig. 2 shows the configuration of the proposed wind-PV hybrid generation system. This hybrid generation system is constituted by a wind power generation branch and a PV power generation branch. The wind power generation branch is composed of a doubly excited PM brushless machine, a three-phase rectifier, a shared battery tank, and a shared inverter. On the other hand, the PV power generation branch is composed of an array of $3 \times 3 \mathrm{PV}$ panels, a SEPIC, a dc/dc converter, a shared battery tank, and a shared inverter. While the SEPIC performs the MPPT for the PV panels, the $\mathrm{dc} / \mathrm{dc}$ converter functions to step up the SEPIC output voltage so that the same battery tank is shared by both the wind power and PV power branches. The inverter is used to convert the dc voltage to the ac voltage so that a typical household can freely utilize electricity from the ac

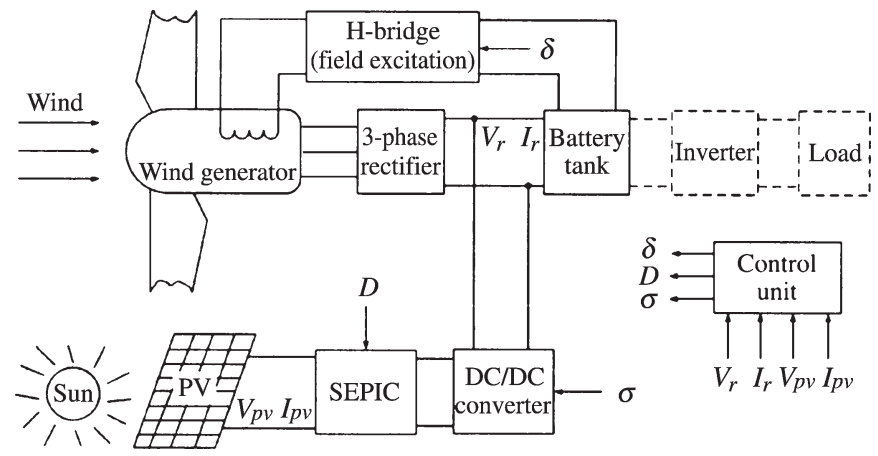

Fig. 2. Proposed wind-PV hybrid generation system.

grid. If there are multiple generation systems connecting to the grid, synchronization among inverters needs to be taken. Since the additional inverter will inevitably cause efficiency loss, the concept of dc microgrid is under active research.

The proposed wind-PV hybrid generation system possesses the following features.

1) Similar to other wind-PV hybrid generation systems [21]-[23], the proposed system utilizes the battery tank and inverter to couple the wind power and PV power branches. Additionally, the PV power can directly be used for dc field excitation of the doubly excited PM generator, rather than conducting $\mathrm{dc} / \mathrm{ac}$ conversion that involves inevitable power loss. Thus, this feature is particularly advantageous for a small-size stand-alone wind-PV system in which the PV panels are mounted onto the pole of the wind generator and the resulting PV power is relatively limited.

2) The wind power generation branch and the PV power generation branch of the hybrid generation system can independently be controlled, hence achieving the MPPT simultaneously.

3) Compared with an individual generation system (the wind power or the PV power), the wind-PV hybrid generation system cannot only harness more energy from nature but also allow the wind power and the PV power to complement one another to some extent between day and night.

4) For the wind power generation branch, the doubly excited PM brushless generator, as shown in Fig. 3, adopts the outer rotor topology [24], which enables the rotor to directly couple with the wind blades. Hence, it can eliminate the complicated mechanical transmission and the relevant costs. Also, since the proposed generator adopts two excitations (PMs and dc field windings), it can flexibly regulates its magnetic field distribution and consequently control the output voltage and power. Thus, without using an additional power converter, which usually exists for the conventional MPPT, the generator itself can adjust the output power at a given wind speed and realize the MPPT.

5) For the PV power generation branch, solar energy is directly converted to electricity by the PV panels and then controlled by a SEPIC for the MPPT. This PV power generation branch processes the merits of simple structure and uncomplicated control. 


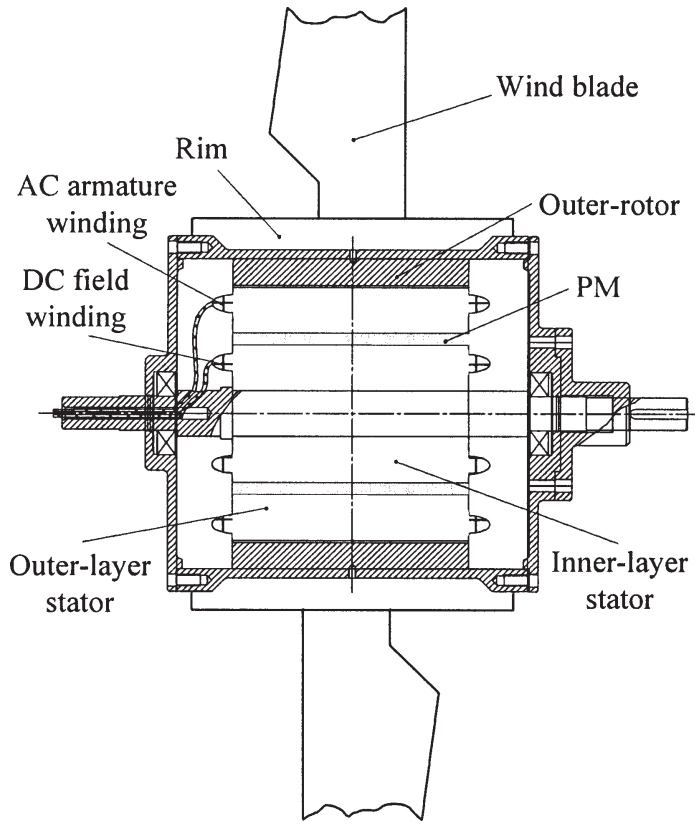

Fig. 3. Proposed wind power generator.

6) As compared with the latest wind-PV hybrid generation systems [21]-[23], the proposed system offers some distinct energy-efficient merits. First, the system in [21] was simply based on parallel operation of a wind-driven induction generator and a battery-coupled PV array via a three-phase inverter. This system cannot perform any efficiency optimization for the wind generator or the PV array. Also, because of inevitable rotor copper loss, the induction generator inherently suffers from relatively lower efficiency than the PM brushless generator. Second, the system in [22] was based on parallel operation of a wind-driven PM synchronous generator and PV panels with a battery bank as energy storage. It utilizes a dc/dc converter to perform the MPPT for the PV panels, while it attempts to use a three-phase rectifier and another $\mathrm{dc} / \mathrm{dc}$ converter to maximize the wind power generation. It is anticipated that this system can offer higher efficiency than the previous one [21] since it utilizes the MPPT to harness PV power and a PM brushless generator to capture wind power. However, the use of a $\mathrm{dc} / \mathrm{dc}$ converter to maximize the wind power generation is too idealized or impractical, which may even impair the originally captured wind power. The whole system of [22] was assessed by computer simulation only. Third, the system in [23] was based on parallel operation of a wind-driven induction generator and a PV array with a battery bank as energy storage. It employs a threephase space-vector PWM ac/dc converter to regulate the $d$ - and $q$-axis current in such a way that the captured wind power can be maximized, while it utilizes a dc/dc converter to perform the MPPT for the PV array. This system is more practical than that in [22] and should offer higher efficiency than that in [21], but it still suffers from relatively low efficiency of the induction generator and relatively complex control due to $d-q$-coordinate transformation. The configuration of the proposed system is similar to that in [22] and [23] but with a special doubly excited PM brushless generator. Hence, it can inherit the high efficiency of PM brushless generators, while it can employ simple dc current control to perform efficiency optimization over a wide range of wind speeds. Therefore, the proposed system can offer higher efficiency than other wind-PV hybrid generation systems.

7) In terms of costs, the proposed hybrid system definitely takes an advantage of lower cost than two individual wind and PV power systems since it can share the same battery tank for energy storage [25]-[27], the same inverter for $\mathrm{dc} / \mathrm{ac}$ conversion, and the same digital hardware for the MPPT. As compared with other wind-PV hybrid generation systems [21]-[23], the proposed system will be relatively more costly than that in [21] and [23] but less costly than that in [22], which is due to the fact that the induction generator is cheaper than the proposed doubly excited PM brushless generator, while the conventional PM synchronous generator desires more PM materials and, hence, more expensive than the proposed one. Nevertheless, taking into account the reduction of operating cost due to efficiency optimization, the proposed system is still more cost effective than that in [21] and [23].

\section{SySTEM ModeLS}

\section{A. MPPT for Wind Power Generation Branch}

Based on the Betz theory, the mechanical power extracted from the wind power can be written as [13], [28]

$$
P_{\text {mech }}=\frac{1}{2} \pi C_{p}(\lambda, \beta) \rho v_{w}^{3} R^{2}
$$

where $C_{p}(\lambda, \beta)$ is the wind power conversion efficiency factor with a typical value of 0.4 or below, $v_{w}$ is the wind speed with a typical range of 3-12 $\mathrm{m} / \mathrm{s}, \rho$ is the air density with a typical value of $1.25 \mathrm{~kg} / \mathrm{m}^{3}, R$ is the wind blade radius, $\beta$ is the blade pitch angle, and $\lambda$ is the TSR that is defined as

$$
\lambda=\frac{\omega R}{v_{w}}
$$

where $\omega$ is the angular speed of the wind turbine shaft or the generator shaft. Taking into account the power losses in the generator and rectifier, the net rectifier output power is

$$
P_{\text {rect }}=\eta P_{\text {mech }}
$$

where $\eta$ is the combined efficiency of the generator and rectifier.

The conversion efficiency factor $C_{p}(\lambda, \beta)$ is maximized as $C_{p-\max }$, based on the condition that the TSR takes the specific value of $\lambda_{\text {opt }}$ and the blade pitch angle $\beta$ is equal to zero. The value of $C_{p-\max }$ is always kept as a constant for all existing maximum power points. Therefore, if $\omega$ can be controlled at different wind speeds, the maxima of $P_{\text {mech }}$ and $P_{\text {rect }}$ can be obtained as

$$
\begin{aligned}
P_{\text {mech-max }} & =\frac{1}{2} \pi\left(\frac{C_{p-\max } \rho R^{5}}{\lambda_{\mathrm{opt}}^{3}}\right) \omega^{3} \\
P_{\text {rect-max }} & =\frac{1}{2} \eta \pi\left(\frac{C_{p-\max } \rho R^{5}}{\lambda_{\mathrm{opt}}^{3}}\right) \omega^{3} .
\end{aligned}
$$




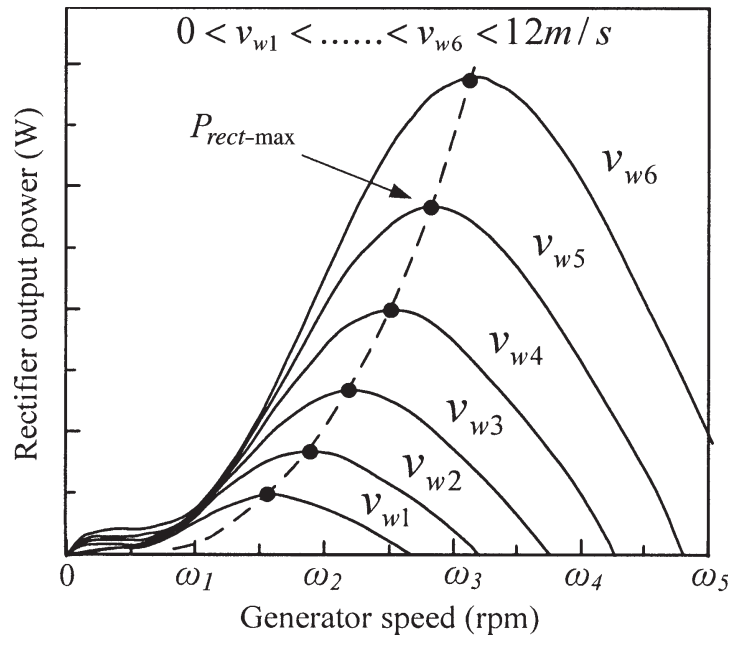

Fig. 4. Wind power curves at various speeds.

Regarding the efficiency $\eta$ as a constant, there is only one variable $\omega$ in (5). Fig. 4 shows typical power curves under different wind speeds. It illustrates that, for a given wind speed, the maximum power point can be determined by

$$
\frac{d P_{\text {rect }}}{d \omega}=0 .
$$

According to the chain rule, (6) can be expressed as

$$
\frac{d P_{\text {rect }}}{d \omega}=\frac{d P_{\text {rect }}}{d V_{r}} \frac{d V_{r}}{d \omega_{e}} \frac{d \omega_{e}}{d \omega}=0
$$

where $V_{r}$ is the rectifier output voltage and $\omega_{e}$ is the electrical angular speed of the generator. This $\omega_{e}$ is related to the turbine shaft (or the generator shaft) speed $\omega$ by

$$
\begin{aligned}
\omega_{e} & =p \omega \\
\frac{d \omega_{e}}{d \omega} & =p>0
\end{aligned}
$$

where $p$ is the number of pole pairs of the generator.

The rectifier output voltage $V_{r}$ is proportional to the generator phase voltage $V_{\mathrm{ph}}$, as given by

$$
V_{r}=k V_{\mathrm{ph}}
$$

where $k$ is a constant with a typical value of $\sqrt{6}$ when open circuited. For normal generation, it yields

$$
\frac{d V_{\mathrm{ph}}}{d \omega_{e}}>0
$$

From (10) and (11), it deduces to

$$
\frac{d V_{r}}{d \omega_{e}}>0 .
$$

Therefore, using (7)-(12), (6) can be rewritten as

$$
\frac{d P_{\text {rect }}}{d V_{r}}=0 .
$$

From Fig. 4, it can be observed that there is only one extreme point of $P_{\text {rect }}$ at a specific $v_{w}$. Hence, there is also only one extreme point of $V_{r}$ to achieve the maximum value of $P_{\text {rect }}$.

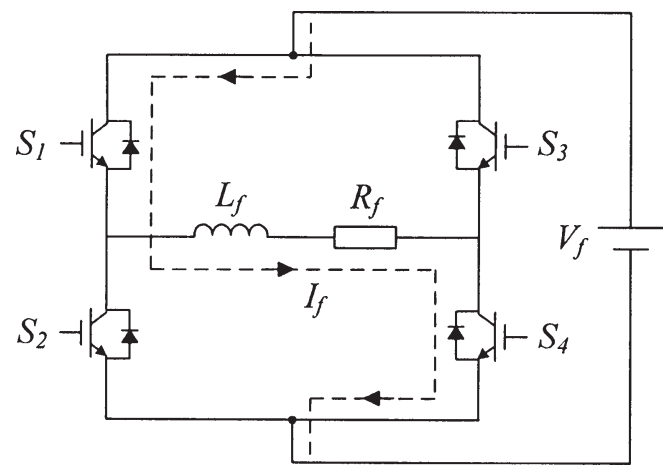

Fig. 5. DC field current control circuit.

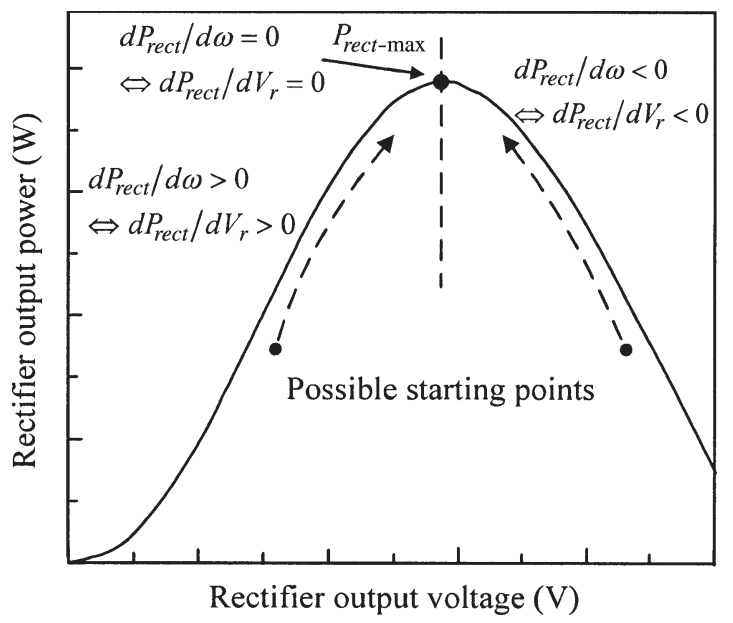

Fig. 6. MPPT process for the wind power generation branch.

For the doubly excited PM brushless machine, its output voltage can be regulated by simply tuning the dc field current [24], which can be expressed as

$$
V_{r}=k V_{\mathrm{ph}}=\frac{k}{2 \pi} C_{e} \Phi \omega
$$

where $C_{e}$ is the electromechanical coefficient and $\Phi$ is the flux linkage. For a given $v_{w}, \omega$ is also fixed. Thus, $V_{r}$ is directly proportional to $\Phi$ and, hence, the dc field winding current $I_{f}$

$$
\begin{gathered}
\Phi \propto I_{f} \\
V_{r} \propto I_{f} .
\end{gathered}
$$

Therefore, the rectifier output voltage and, hence, power can be regulated by simply tuning the dc field current.

Fig. 5 shows the dc field current control circuit. The H-bridge circuit functions to provide bidirectional control of dc field current so that the dc field coil can provide positive field to strengthen the PM field or provide negative field to weaken the PM field, hence achieving flexible flux control for efficiency optimization. It should be noted that there is almost no electromagnetic coupling between the dc field windings and the ac armature windings due to the special structure of the proposed generator. The amplitude of the field current can easily be regulated by adjusting the duty cycle $\delta$ of the $\mathrm{H}$-bridge circuit.

Fig. 6 shows the MPPT process under a specific wind speed, which is based on the PAO method. If the starting point is from 
TABLE I

PAO ALGORITHM FOR WIND POWER GENERATION

\begin{tabular}{cccc}
\hline Perturbation & $\begin{array}{c}\text { Change in } \\
\text { voltage }\end{array}$ & $\begin{array}{c}\text { Change in } \\
\text { power }\end{array}$ & $\begin{array}{c}\text { Next } \\
\text { perturbation }\end{array}$ \\
\hline Positive & Positive & Positive & Positive \\
Negative & Negative & Negative & Positive \\
Positive & Positive & Negative & Negative \\
Negative & Negative & Positive & Negative \\
\hline
\end{tabular}

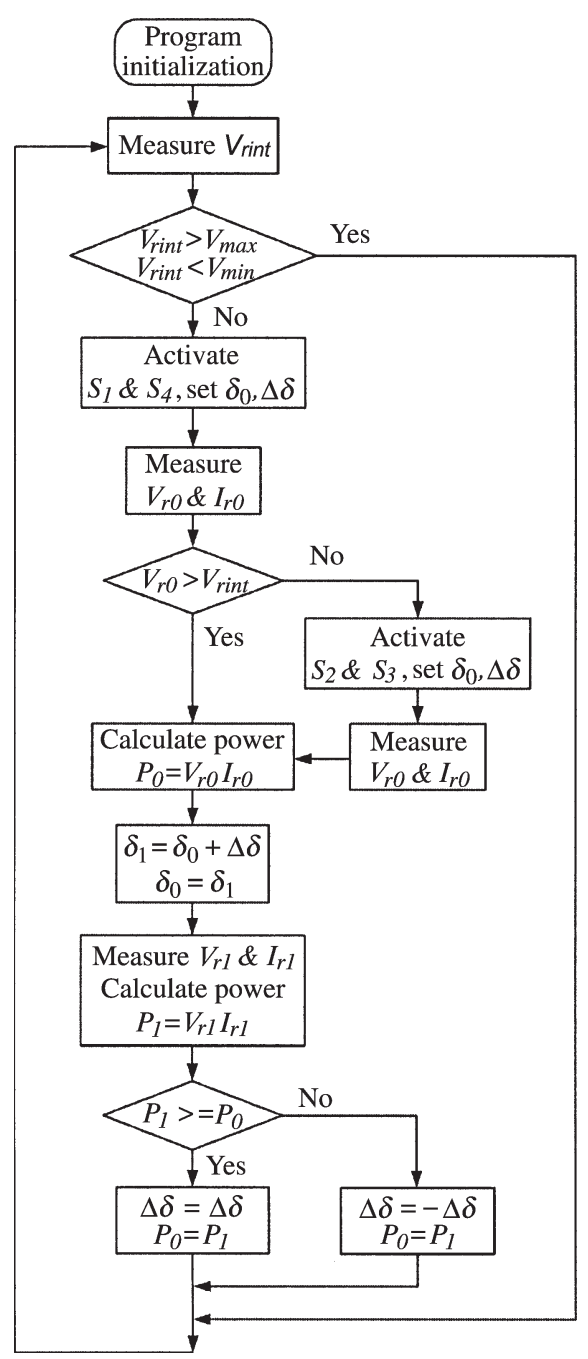

Fig. 7. MPPT flowchart for the wind power generation branch.

the left-hand side of the maximum power point, the voltage adjustment follows the direction of $d P_{\text {rect }} / d V_{r}$. Thus, the increment of $V_{r}$ increases $P_{\text {rect }}$. In contrast, if the starting point is from the right-hand side of the maximum power point, the voltage adjustment is opposite to the direction of $d P_{\text {rect }} / d V_{r}$. Thus, the decrement of $V_{r}$ increases $P_{\text {rect }}$. Therefore, if there is an increase in power, the subsequent perturbation will be kept unchanged until the maximum power point is reached; otherwise, if there is a decrease in power, the perturbation will be reversed. This perturbation algorithm is summarized in Table I. The flowchart of the whole MPPT process is shown in Fig. 7, where $V_{r \text { int }}$ is the initial value of $V_{r}, V_{\max }$ and $V_{\min }$ are the maximum and minimum settings of $V_{r}, \delta_{0}$ and $\Delta \delta$ are the initial value and step size of the duty cycle of the H-bridge

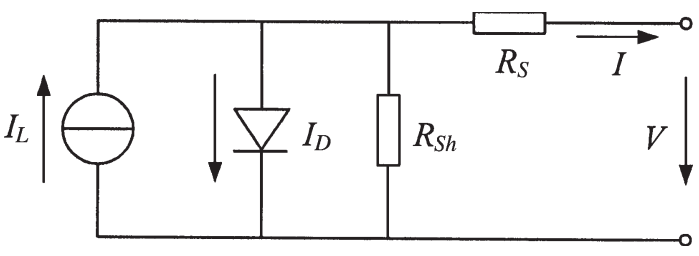

Fig. 8. Equivalent circuit of the PV panel.

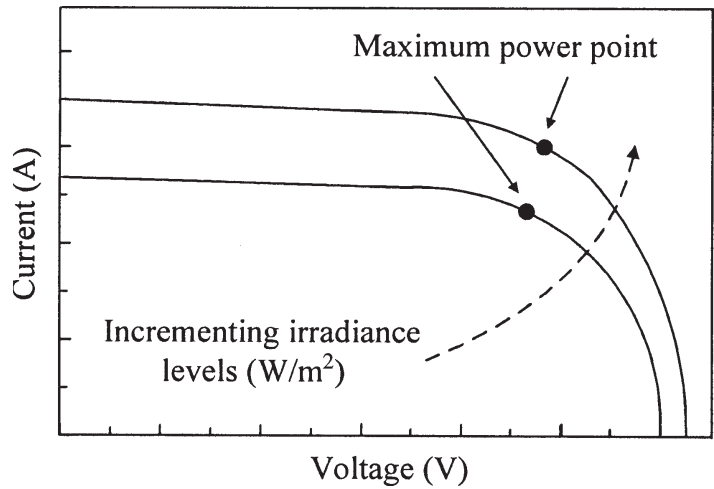

Fig. 9. Typical current-voltage curves of the PV panel.

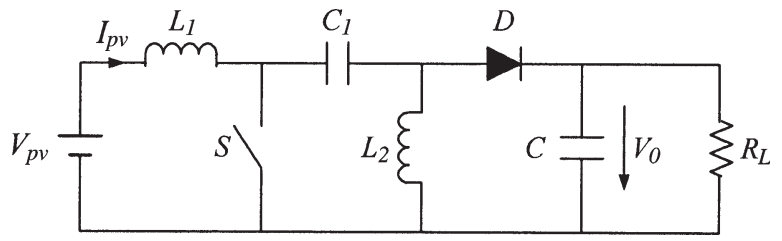

Fig. 10. SEPIC circuit topology.

circuit, respectively, and $V_{\mathrm{rk}}$ and $I_{\mathrm{rk}}$ are the $k$ th steps of $V_{r}$ and $I_{r}$, respectively.

\section{B. MPPT for PV Power Generation Branch}

Fig. 8 shows the equivalent circuit of a PV module. Its mathematical expression can be written as [29], [30]

$$
I=I_{L}-I_{D}\left[\exp \left(\frac{q V+q I R_{S}}{A K T}\right)-1\right]-\frac{V+I R_{S}}{R_{S h}}
$$

where $V$ is the output voltage of the PV module, $I$ is the current output, $I_{D}$ is the diode saturation current, $q$ is the electron charge, $A$ is the material factor of the p-n junction, $K$ is the Boltzmann constant, $T$ is the absolute temperature, $R_{S}$ is the intrinsic series resistance, and $R_{S h}$ is the parallel resistance. From (17), a typical set of current-voltage curves of the PV module can be obtained, as shown in Fig. 9. It can be seen that when the voltage increases, the current goes down. Therefore, the maximum power point occurs at the corner. Hence, by properly tuning the output voltage, the MPPT can be performed under different irradiance levels.

Although different MPPT methods have been proposed for $\mathrm{PV}$ power generation, the $\mathrm{PAO}$ one is still the most common method in practice due to its simplicity and system independence. Thus, the proposed PV power generation branch adopts this method to perform the MPPT.

Fig. 10 shows the circuit topology of the SEPIC for the PV power generation branch, where $V_{\mathrm{pv}}$ and $I_{\mathrm{pv}}$ are the output 


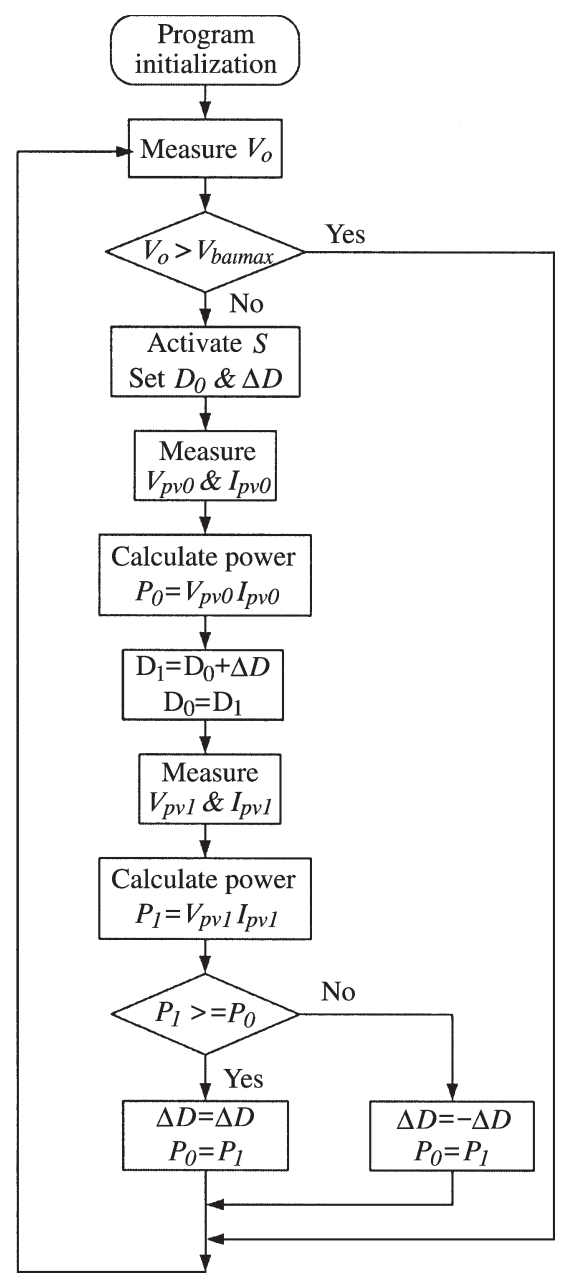

Fig. 11. MPPT flowchart for the PV power generation branch.

voltage and current of the PV panels, respectively, $L_{1}$ and $L_{2}$ are the circuit inductors, $C_{1}$ and $C$ are the circuit capacitors, and $R_{L}$ is the load resistor. The SEPIC takes the definite advantage of nonpulsating input current, as well as the capability of both step-up and step-down features. By operating the SEPIC in discontinuous capacitor voltage mode, the input voltage $V_{i}$, output voltage $V_{o}$, and input resistance $R_{i}$ can be expressed as

$$
\begin{aligned}
V_{i} & =V_{\mathrm{pv}}=\frac{I_{\mathrm{pv}} T_{s}}{C_{1}}(1-D)^{2} \\
V_{o} & =\frac{d}{1-D} V_{\mathrm{pv}} \\
d & =\sqrt{\frac{2 R_{L} C_{1}}{T_{s}}} \\
R_{i} & =\frac{V_{\mathrm{pv}}}{I_{\mathrm{pv}}}=\frac{T_{s}}{C_{1}}(1-D)^{2}
\end{aligned}
$$

where $T_{s}$ and $D$ are the switching period and duty cycle of the control signal, respectively. From (21), it can be seen that $R_{i}$ changes with $D$, namely, $R_{i}$ decreases with the increase of $D$. Hence, by properly perturbing the duty cycle, the input resistance of the SEPIC can match with the load resistance, hence achieving the maximum power transfer. Fig. 11 shows the corresponding flowchart for the MPPT, where $V_{\text {bat max }}$ is the maximum charging voltage of the battery tank, $D_{0}$ and $\Delta D$

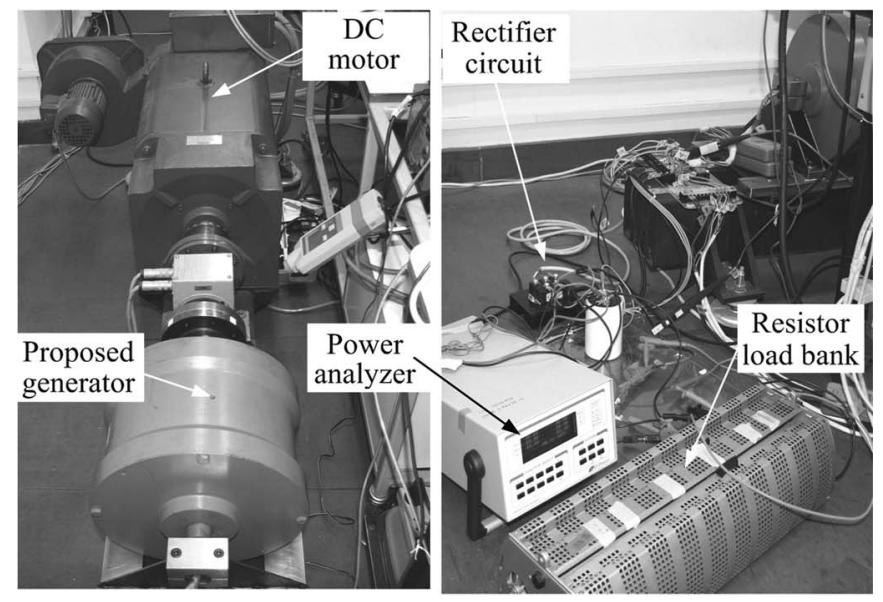

(a)

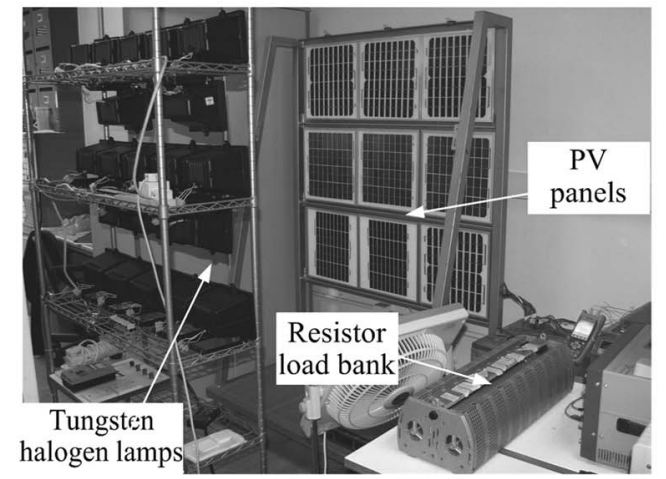

(b)

Fig. 12. Prototype of the proposed hybrid generation system. (a) Wind power generation branch. (b) PV power generation branch.

are the initial value and step size of the duty cycle of the control signal, respectively, and $V_{\mathrm{pvk}}$ and $I_{\mathrm{pvk}}$ are the $k$ th steps of $V_{\mathrm{pv}}$ and $I_{\mathrm{pv}}$, respectively.

\section{RESUlTS}

Fig. 12 shows the prototype of the whole wind-PV hybrid generation system. In this system, the dc motor is fed by a four-quadrant programmable power supply, which can realtime control the rotor speed and torque in accordance with realistic wind profile characteristics. Meanwhile, a group of tungsten halogen lamps are controlled by a programmable light dimmer to emulate various sunlight irradiances.

First, the performances of the wind power generation branch are assessed. Fig. 13 shows the rectifier output power characteristics under different speeds. It verifies that the characteristics of the output power versus the output voltage have an obvious maximum power point under each speed. Also, these maximum power points can be achieved by simply regulating the dc field current. Moreover, the characteristics of the maximum output power and the combined generator-rectifier efficiency versus the speed are shown in Fig. 14. It can be observed that both the maximum power point and efficiency increase with the speed. The maximum power point increment is simply due to the increase of input wind power. The efficiency increment is due to the fact that the rated speed of the proposed generator is designed at $600 \mathrm{r} / \mathrm{min}$ (corresponding to the wind speed of 


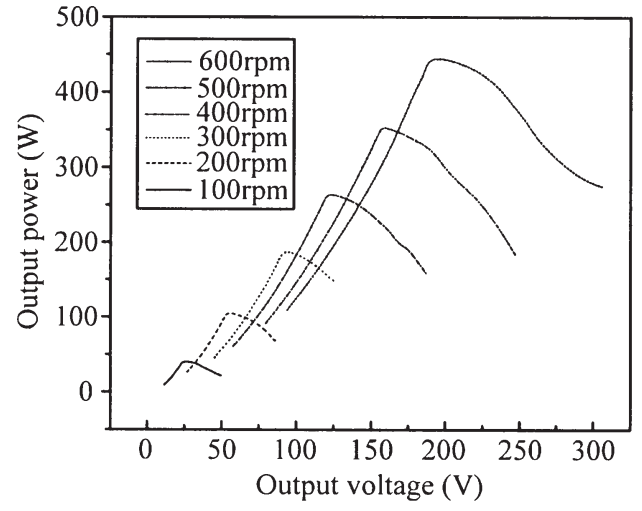

(a)

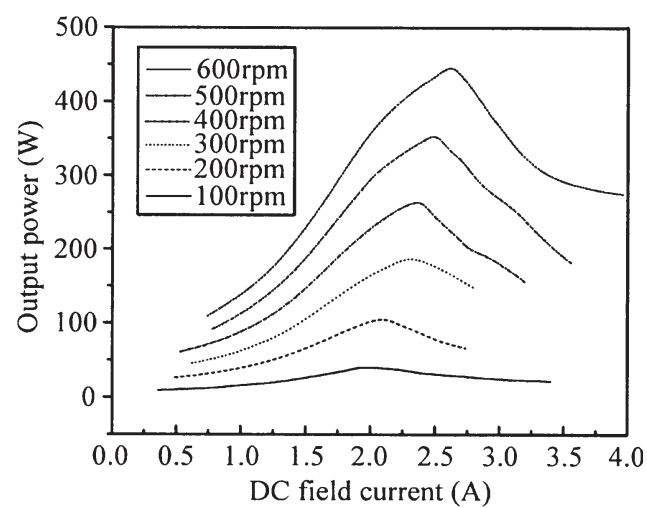

(b)

Fig. 13. Wind generator output power characteristics under different speeds. (a) Versus output voltage. (b) Versus dc field current.

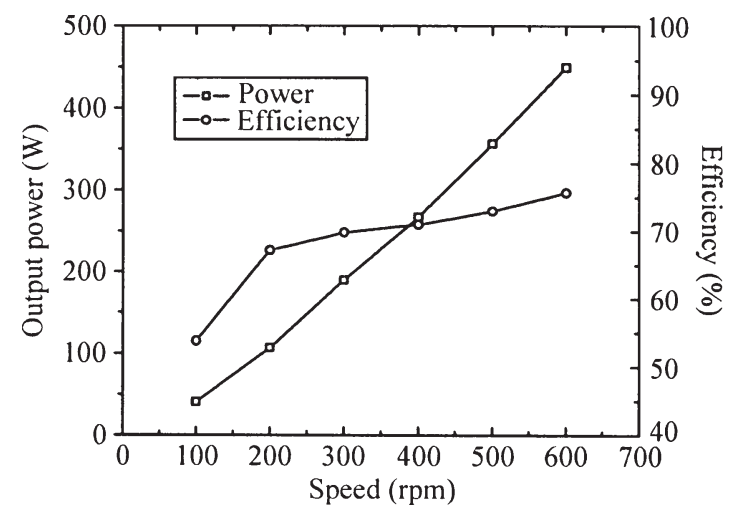

Fig. 14. Wind generator characteristics of maximum output power and efficiency versus speed.

$15 \mathrm{~m} / \mathrm{s})$. In general, the combined generator-rectifier efficiency of the conventional wind power generation system is in the range of $50 \%-75 \%$ under the wind speed of $4-12 \mathrm{~m} / \mathrm{s}$. For the proposed wind power generation system, it can be seen that its efficiency is already over $70 \%$ when the rotor speed is $300 \mathrm{r} / \mathrm{min}$ (corresponding to the wind speed of $9 \mathrm{~m} / \mathrm{s}$ ). Hence, the proposed wind power generation branch can efficiently convert wind energy to electrical energy over the major speed range. In order to evaluate the validity of MPPT as compared with the case that adopts a fixed dc field current, the middle value ( $2 \mathrm{~A}$ ) of the whole field current range (0-4 A) is selected. The use of dc field current that is equal to $2 \mathrm{~A}$ almost corresponds to the maximum power point at $100 \mathrm{r} / \mathrm{min}$. Fig. 15 shows

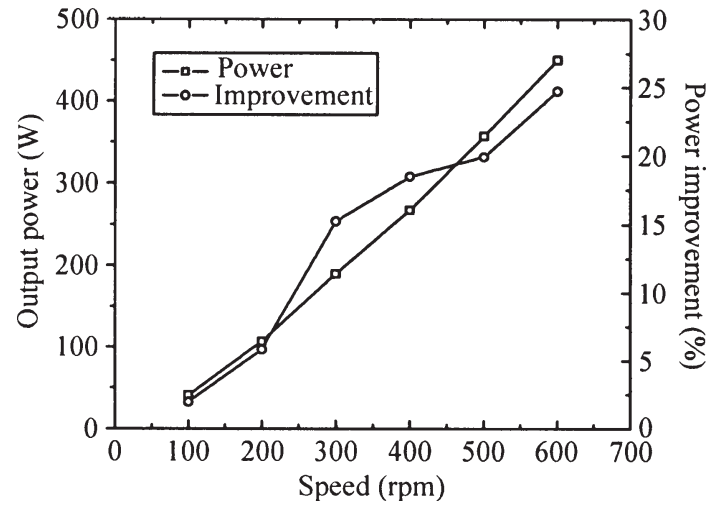

Fig. 15. Wind generator characteristics of maximum output power and power improvement versus speed with MPPT.

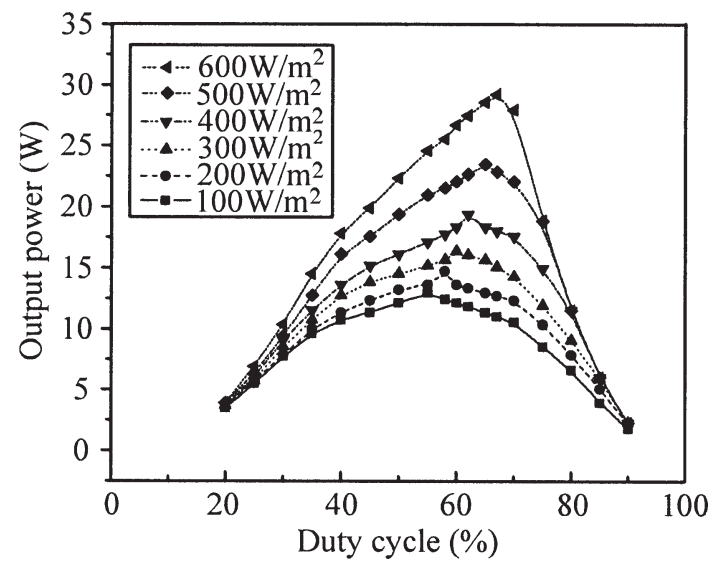

Fig. 16. PV panel output power characteristics versus duty cycle under different irradiances.

the characteristics of the maximum output power and power improvement as compared with the case under a fixed dc field current of $2 \mathrm{~A}$ versus the speed under MPPT. It can be seen that the power improvement is significant, which is about $25 \%$ at the rotor speed of $600 \mathrm{r} / \mathrm{min}$.

Second, the PV power generation branch characteristics are analyzed. Fig. 16 shows the characteristics of the PV output power versus the duty cycle under different irradiances. It verifies that the PV power generation branch can readily perform the MPPT and achieve the maximum output power at a given irradiance. In order to evaluate the validity of MPPT as compared with the case that adopts a fixed duty cycle, the middle value $(50 \%)$ of the whole duty cycle range $(0 \%-100 \%)$ is selected. The use of duty cycle that is equal to $50 \%$ almost corresponds to the maximum power point at $100 \mathrm{~W} / \mathrm{m}^{2}$. The characteristics of the maximum output power and power improvement versus the irradiance are shown in Fig. 17. It can be found that the maximum output power increases with the irradiance, which well agrees with the principle of the PV panels. Also, the power improvement under MPPT as compared with the case under the fixed duty cycle of $50 \%$ is significant, which is about $30 \%$ at the irradiance of $600 \mathrm{~W} / \mathrm{m}^{2}$. Such an improvement agrees with the expectation since the converter operating at a fixed duty cycle cannot perform effective power transfer.

Third, the wind-PV hybrid generation characteristics are evaluated. Fig. 18 shows the total output power under MPPT 


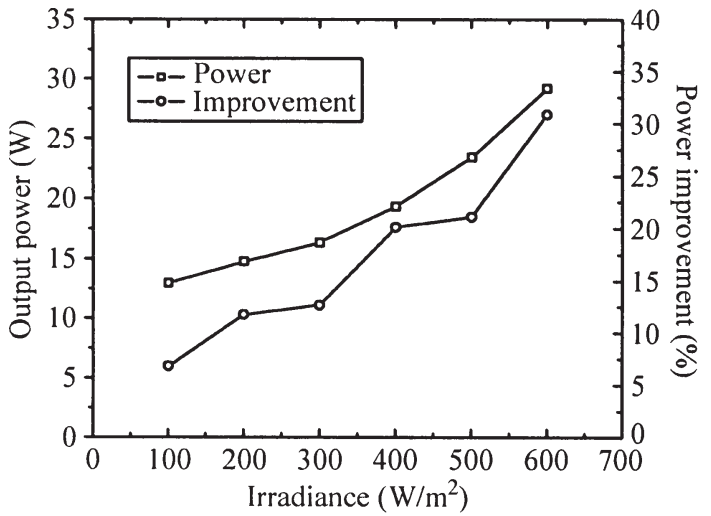

Fig. 17. PV panel characteristics of maximum output power and power improvement with MPPT.

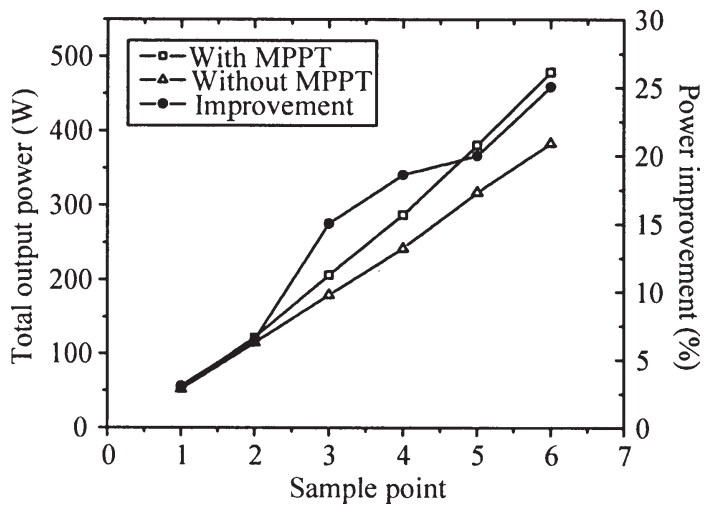

Fig. 18. Characteristics of total output power and power improvement.

as compared with the case under the fixed dc field current of $2 \mathrm{~A}$ and the fixed duty cycle of $50 \%$. The corresponding power improvement is from $3 \%$ to $25.1 \%$. Hence, it verifies that the proposed system with MPPT can efficiently extract energy from the wind and PV sources. It is worthy to note that the prototype is mainly used for experimental verification. Thus, it is designed at low power levels that adversely affect the efficiency. Since some major losses such as the core loss and the windage and friction losses of the generator are independent of the power level, it is expected that the efficiency will be much better when the power level is elevated to the order of kilowatts.

Finally, Fig. 19(a) shows typical daily profiles of wind speed and solar irradiance in October in Hong Kong. Fig. 19(b) shows the corresponding output powers. It can be seen that the wind is weak at most daytime and becomes strong at nighttime (particularly at midnight), while sunshine occurs at daytime and reaches the peak at noon. Hence, it confirms that the wind power and PV power are complementary to some extent.

\section{CONClusion}

In this paper, a new wind-PV hybrid generation system has been proposed and implemented. This stand-alone hybrid generation system can fully utilize the characteristics of the proposed wind generator and the PV panels to extract the maximum power from the wind and solar energy sources. Namely, the MPPT of the doubly excited PM brushless generator is achieved by online tuning its dc field current, while the MPPT

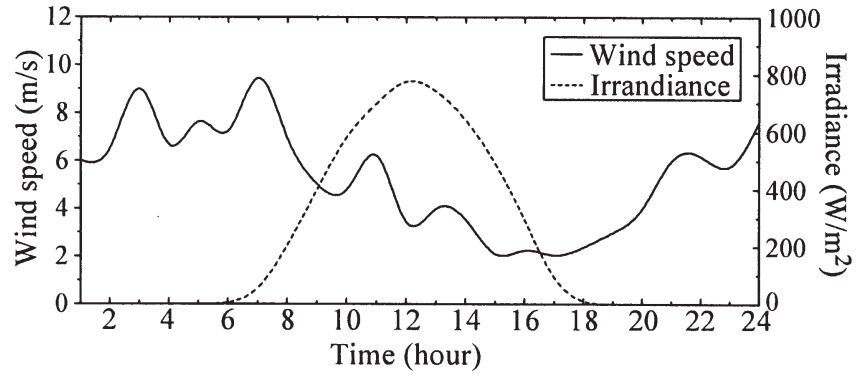

(a)

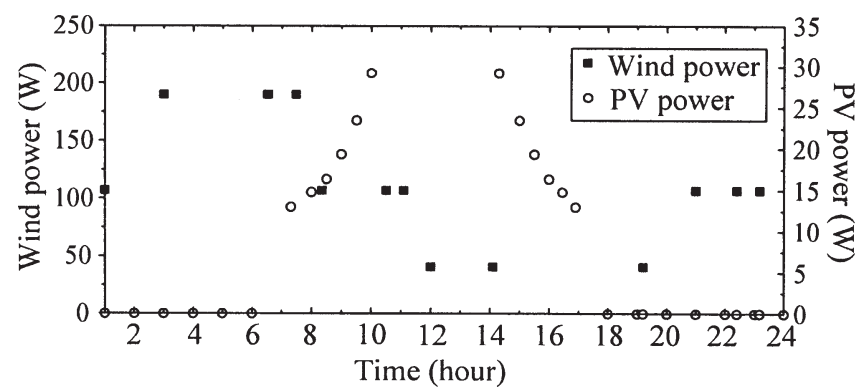

(b)

Fig. 19. Complementary wind-PV hybrid generation. (a) Daily profiles of wind speed and irradiance. (b) Daily profiles of wind power and PV power.

of the PV panels is attained by online tuning the duty cycle of the SEPIC. Also, this hybrid generation system takes a distinct merit that the wind power and PV power inherently complement one another to certain extent, hence facilitating continuous output power from day to night.

\section{REFERENCES}

[1] Y.-M. Cheng, Y.-C. Liu, S.-C. Hung, and C.-S. Cheng, "Multi-input inverter for grid-connected hybrid PV/wind power system," IEEE Trans. Power Electron., vol. 22, no. 3, pp. 1070-1076, May 2007.

[2] K. T. Chau, Y. B. Li, J. Z. Jiang, and S. Niu, "Design and control of a PM brushless hybrid generator for wind power application," IEEE Trans. Magn., vol. 42, no. 10, pp. 3497-3499, Oct. 2006.

[3] L. Jian, K. T. Chau, and K. T. Chau, "A magnetic-geared outer-rotor permanent-magnet brushless machine for wind power generation," IEEE Trans. Ind. Appl., vol. 45, no. 3, pp. 954-962, May/Jun. 2009.

[4] K. T. Chau, C. C. Chan, and C. Liu, "Overview of permanent-magnet brushless drives for electric and hybrid electric vehicles," IEEE Trans. Ind. Electron., vol. 55, no. 6, pp. 2246-2257, Jun. 2008.

[5] K. T. Chau, Y. S. Wong, and C. C. Chan, "An overview of energy sources for electric vehicles," Energy Convers. Manage., vol. 40, no. 10, pp. 10211039, Jul. 1999.

[6] K. T. Chau and Y. S. Wong, "Hybridization of energy sources in electric vehicles," Energy Convers. Manage., vol. 42, no. 9, pp. 1059-1069, Jun. 2001.

[7] G. O. Cimuca, C. Saudemont, B. Robyns, and M. M. Radulescu, "Control and performance evaluation of a flywheel energy-storage system associated to a variable-speed wind generator," IEEE Trans. Ind. Electron., vol. 53, no. 4, pp. 1074-1085, Apr. 2006.

[8] S. Niu, K. T. Chau, J. Z. Jiang, and C. Liu, "Design and control of a new double-stator cup-rotor permanent-magnet machine for wind power generation," IEEE Trans. Magn., vol. 43, no. 6, pp. 2501-2503, Jun. 2007.

[9] C. Yu, K. T. Chau, and J. Z. Jiang, "A flux-mnemonic permanent magnet brushless machine for wind power generation," J. Appl. Phys., vol. 105, no. 7, pp. 07F 114-1-07F 114-3, Apr. 2009.

[10] D. A. Torrey, "Switched reluctance generators and their control," IEEE Trans. Ind. Electron., vol. 49, no. 1, pp. 3-14, Feb. 2002.

[11] Y. Fan, K. T. Chau, and M. Cheng, "A new three-phase doubly salient permanent magnet machine for wind power generation," IEEE Trans. Ind. Appl., vol. 42, no. 1, pp. 53-60, Jan./Feb. 2006.

[12] Q. Wang and L. Chang, "An intelligent maximum power extraction algorithm for inverter-based variable speed wind turbine system," IEEE Trans. Power Electron., vol. 19, no. 5, pp. 1242-1249, Sep. 2004. 
[13] E. Koutroulis and K. Kalaitzakis, "Design of a maximum power tracking system for wind-energy-conversion applications," IEEE Trans. Ind. Electron., vol. 53, no. 2, pp. 486-494, Apr. 2006.

[14] C. Yu and K. T. Chau, "Thermoelectric automotive waste heat energy recovery using maximum power point tracking," Energy Convers. Manage., vol. 50, no. 6, pp. 1506-1512, Jun. 2009.

[15] T. Esram and P. L. Chapman, "Comparison of photovoltaic array maximum power point tracking techniques," IEEE Trans. Energy Convers., vol. 22, no. 2, pp. 439-449, Jun. 2007.

[16] J. T. Bialasiewicz, "Renewable energy systems with photovoltaic power generators: Operation and modeling," IEEE Trans. Ind. Electron., vol. 55, no. 7, pp. 2752-2758, Jul. 2008.

[17] W. Xiao, N. Ozog, and W. G. Dunford, "Topology study of photovoltaic interface for maximum power point tracking," IEEE Trans. Ind. Electron., vol. 54, no. 3, pp. 1696-1704, Jun. 2007.

[18] R. Gules, J. D. P. Pacheco, H. L. Hey, and J. Imhoff, "A maximum power point tracking system with parallel connection for PV stand-alone applications," IEEE Trans. Ind. Electron., vol. 55, no. 7, pp. 2674-2683, Jul. 2008.

[19] N. Femia, G. Lisi, G. Petrone, G. Spagnuolo, and M. Vitelli, "Distributed maximum power point tracking of photovoltaic arrays: Novel approach and system analysis," IEEE Trans. Ind. Electron., vol. 55, no. 7, pp. 26102621, Jul. 2008

[20] H. Patel and V. Agarwal, "Maximum power point tracking scheme for PV systems operating under partially shaded conditions," IEEE Trans. Ind. Electron., vol. 55, no. 4, pp. 1689-1698, Apr. 2008.

[21] S. A. Daniel and N. AmmasaiGounden, "A novel hybrid isolated generating system based on PV fed inverter-assisted wind-driven induction generations," IEEE Trans. Energy Convers., vol. 19, no. 2, pp. 416-422, Jun. 2004.

[22] F. Valenciaga and P. F. Puleston, "Supervisor control for a stand-alone hybrid generation system using wind and photovoltaic energy," IEEE Trans. Energy Convers., vol. 20, no. 2, pp. 398-405, Jun. 2005

[23] S.-K. Kim, J.-H. Jeon, C.-H. Cho, J.-B. Ahn, and S.-H. Kwon, "Dynamic modeling and control of a grid-connected hybrid generation system with versatile power transfer," IEEE Trans. Ind. Electron., vol. 55, no. 4, pp. 1677-1688, Apr. 2008.

[24] C. Liu, K. T. Chau, J. Z. Jiang, and L. Jian, "Design of a new outer-rotor permanent magnet hybrid machine for wind power generation," IEEE Trans. Magn., vol. 44, no. 6, pp. 1494-1497, Jun. 2008.

[25] W. X. Shen, C. C. Chan, E. W. C. Lo, and K. T. Chau, "Adaptive neuro-fuzzy modeling of battery residual capacity for electric vehicles," IEEE Trans. Ind. Electron., vol. 49, no. 3, pp. 677-684, Jun. 2002.

[26] K. T. Chau, K. C. Wu, C. C. Chan, and W. X. Shen, "A new battery capacity indicator for nickel-metal hydride battery powered electric vehicles using adaptive neuro-fuzzy inference system," Energy Convers. Manage., vol. 44, no. 13, pp. 2059-2071, Aug. 2003.

[27] K. T. Chau, K. C. Wu, and C. C. Chan, "A new battery capacity indicator for lithium-ion battery powered electric vehicles using adaptive neurofuzzy inference system," Energy Convers. Manage., vol. 45, no. 11/12, pp. 1681-1692, Jul. 2004.

[28] Y. Fan, K. T. Chau, and S. Niu, "Development of a new brushless doubly fed doubly salient machine for wind power generation," IEEE Trans. Magn., vol. 42, no. 10, pp. 3455-3457, Oct. 2006.

[29] N. Mutoh, M. Ohno, and T. Inoue, "A method for MPPT control while searching for parameters corresponding to weather conditions for PV generation systems," IEEE Trans. Ind. Electron., vol. 53, no. 4, pp. 10551065, Jun. 2006.

[30] F. Liu, S. Duan, F. Liu, B. Liu, and Y. Kang, "A variable step size INC MPPT method for PV systems," IEEE Trans. Ind. Electron., vol. 55, no. 7, pp. 2622-2628, Jul. 2008.

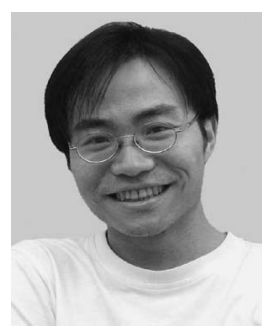

Chunhua Liu (S'05-M'10) received the B.Eng. and M.Eng. degrees from the Beijing Institute of Technology, Beijing, China, in 2002 and 2005, respectively, and the Ph.D. degree from The University of Hong Kong, Pokfulam, Hong Kong, in 2009.

He currently serves as a Researcher with the Department of Electrical and Electronic Engineering, The University of Hong Kong. His research interests include electric drives, electric vehicles, renewable energy developments, and smart grid systems. He currently focuses on the design of permanent-magnet brushless motors, integrated starter-generator systems, and electric variable transmission systems for hybrid electric vehicles, as well as the development of wind power and photovoltaic generation systems.

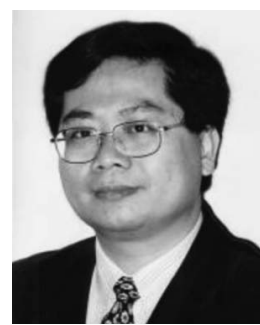

K. T. Chau (M'89-SM'04) received the B.Sc. (Eng.) (first-class honors), M.Phil., and Ph.D. degrees in electrical and electronic engineering from The University of Hong Kong, Hong Kong, in 1988, 1991, and 1993, respectively.

He is currently a Professor in the Department of Electrical and Electronic Engineering, The University of Hong Kong, where he is also the Director of the International Research Center for Electric Vehicles. His teaching and research interests mainly include electric vehicles, electric drives, and power electronics. In these areas, he has published over 300 refereed technical papers. $\mathrm{He}$ is also a coauthor of the monograph entitled Modern Electric Vehicle Technology (Oxford Univ. Press, 2001).

Dr. Chau is a Fellow of the Institution of Engineering and Technology, U.K., He was the recipient of the Outstanding Young Researcher Award in 2003, the University Teaching Fellowship Award in 2004, and the Award for Innovative Excellence in Teaching, Learning, and Technology in 2005.

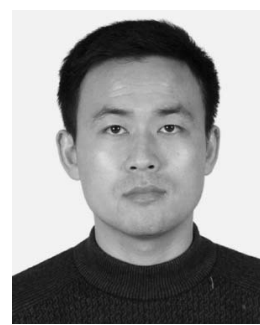

Xiaodong Zhang (S'08) received the B.Eng. and M.Eng. degrees from the Department of Automation, Tianjin University, Tianjin, China, in 2002 and 2005 , respectively. He is currently working toward the Ph.D. degree in the Department of Electrical and Electronic Engineering, The University of Hong Kong, Hong Kong.

His research interests include applications of renewable energy sources, switching-mode power supplies, and hybrid electric vehicles. 